\title{
Etiology of Severe Anemia in Children at a Tertiary Care Hospital.
}

\author{
Suresh Babu Mendu ${ }^{1}$, Vedavyasa Srigade ${ }^{2}$ \\ ${ }^{1}$ Associate Professor of Paediatrics, Government Medical College, Siddipet, Telangana, ${ }^{2}$ Associate Professor, Department of Paediatrics, Niloufer Hospital, Hyderabad.
}

\section{Abstract}

Background: Public health significance of anemia in children was classified as severe in India. Severe anemia $(\mathrm{Hb}<7 \mathrm{~g} / \mathrm{dL})$ significantly increases the risk of death. Critical diagnostic evaluation and a thorough work-up make the accurate diagnosis of intrinsic red cell abnormalities feasible. Review of etiology helps to formulate strategies to prevent them, and to know the degree of achievement of the targets. Objectives: The aim of the present study was to identify the etiology of severe anemia. Subjects and Methods: It is a retrospective record based study done at a tertiary care center. All new severe anemia cases aged 1 month to 18 yrs, which were admitted on Monday from Jan 2017 to Dec 2017 were included. Previously worked up cases coming for transfusions and anemia due to bleeding were excluded. Details of history, physical examination and work-up were obtained for justification of diagnosis based on existing evidence. Results: 112 children were included. Mean age was 3.94 yrs (+/_3.52) (Range: 1 month-13 years), median and mode were 3 years. Male to female ratio was $1.95: 1$. 51\% of severe anemia cases were due to iron deficiency. $11.6 \%$ had confirmed $\beta$-Thalassemia Trait (BTT) and 18.75\% had suspected Thalassemia Trait (TT). Other causes of severe anemia were: folate deficiency (13.4\%), B12 deficiency (1.8\%), hereditary spherocytosis (HS) (7.1\%), marrow replacement by acute leukemia $(6.25 \%)$, aplastic anemia $(2.7 \%)$, malaria $(2.7 \%)$, and antiretroviral therapy induced anemia $(0.9 \%)$. HS was the second most common cause of hemolytic anemia after thalassemias. Conclusion: Though a number of nutrition based initiatives have been initiated in the country, the burden of preventable iron deficiency, contributing to severe anemia cases is enormous, signifying the need for more effective programs to be implemented in India. Folate should be supplemented to all children with anemia irrespective of the cause. Essential workup with proper interpretation of investigations for arriving at diagnosis prior to transfusing the child is obligatory.

Keywords: Severe anemia, iron deficiency, thalassemia, folate, B12, hereditary spherocytosis.

Corresponding Author: Dr. Vedavyasa Srigade, 1-1-405/8/1, Near St. Gregorios Cathedral, Gandhinagar, Hyderabad, India. 500080.

Received: August 2018

Accepted: September 2018

\section{Introduction}

Anemia is defined physiologically as hemoglobin $(\mathrm{Hb})$ level too low to meet cellular oxygen demands and statistically as $\mathrm{Hb}$ level <2 SD below the mean for age, gender, race, developmental stage and altitude levels. Indian national family health survey - 4 (2015 -16) reveals the prevalence of anemia $(\mathrm{Hb}<11 \mathrm{~g} / \mathrm{dL})$ in children aged 6-59 months as $58.5 \% .^{[1]}$ In developed countries it is less than $15 \% .{ }^{[2]}$ In India $1.8 \%$ (95\% CI: 0.4 to 4.9 ) of children aged 6-59 months have severe anemia $(\mathrm{Hb}<7 \mathrm{~g} / \mathrm{dL})$ and the level of public health significance was classified as severe, whereas it is $0-0.2 \%$ in developed nations. ${ }^{[2]}$ Anemia is present at the time of paediatric intensive care unit (PICU) admission in $33 \%$ of children, and an additional $41 \%$ develop anemia during their PICU stay. Severe anemia can significantly increase the risk of death. Only a red blood cell (RBC) transfusion can rapidly treat a severe anemia. In stable PICU patients, RBC transfusion is probably not required if the hemoglobin concentration is above $7 \mathrm{~g} / \mathrm{dL}$, unless the patient has a cyanotic cardiac condition. ${ }^{[3]}$ Anemic children are susceptible to develop frequent infections and may present with infection.

Anemia can be a result of decreased production (anemia in bone marrow failure syndromes), marrow replacement (malignancies, osteopetrosis and myelofibrosis), ineffective erythropoiesis (iron-deficiency anemia(IDA), lead poisoning, anemia of chronic disease, megaloblastic anemias due to B12 or folate deficiency), increased loss (due to trauma, bleeding, surgery, blood sampling), and destruction of red blood cells ( hemolytic anemias: immune hemolytic anemia, red cell membrane disorders, red cell enzyme deficiency, hemoglobinopathies, microangiopathic hemolytic anemias (MAHA), hemophagocytic lymphohistiocytosis (HLH), and hypersplenism).

Anemia is also classified as microcytic, normocytic, or macrocytic according to the size of RBC. The most common causes of hypochromic microcytic anemia are IDA and thalassemia trait (TT). Some IDA patients may have normocytic RBC. IDA is highly prevalent in India and much larger population is having iron deficiency(ID) without anemia. Besides IDA, ID has several non-haematological consequences including effects on neurocognition and immune function. IDA risk is high during periods of rapid growth and erythroid expansion, especially in premature 
neonates, toddlers, preschool children and adolescents. Association of ID with febrile convulsions, pica, breath holding spells, restless leg syndrome and thrombosis is increasingly being recognized.

Macrocytic anemia needs evaluation for vitamin B12 and folate deficiencies, hypothyroidism, hepatic disease, and bone marrow disorders. B12 deficiency is caused by either inadequate intake, inadequate bio-availability or malabsorption. Low maternal B12 status, extended breastfeeding and a low intake of animal food after weaning are major risk factors for B12 deficiency.

Hemoglobinopathies, the most common human monogenic disorders, are quantitative and/or qualitative abnormalities in Hb synthesis due to $\beta$ - or an $\alpha$-globin gene defects. Of these $\beta$ thalassemia and sickle cell disease (SCD) are the most clinically significant public health problems. A repeat thalassaemia screen should be performed if microcytosis persists despite correction of ID. None of the Cell counterbased formulas and parameters can be $100 \%$ sensitive and specific, maybe due to atypical $\beta$-thalassemia carriers, normal MCV and $\mathrm{MCH}$ values $(\alpha-$ and $\beta$-thalassemia interaction) and a normal $\mathrm{HbA} 2$ level (coinheritance of $\delta$ and $\beta$-thalassemia, some mild $\beta$-gene mutations, and $\gamma \delta \beta$ thalassemia), are therefore, important only for screening in areas of high prevalence of BTT, and these cases should undergo further confirmatory tests. $20-30 \%$ of $\alpha$ and $\beta$ TT have coexistent ID, some even suffer from severe IDA and they improve if treated with iron [4-7]. Many nonhematologist physicians may not be aware of the possible coexistence of ID with TT. Proper assessment of iron level among the TT should be done.

Hereditary spherocytosis (HS) is a heterogeneous group of diseases affecting erythrocyte membrane proteins resulting in decreased deformability of the erythrocytes and their accelerated degradation in the spleen. A low reticulocyte count with normocytic anemia in infants and children suggests impaired bone marrow function.

Usually, the presentation of anemia is non-urgent, and a thorough work-up can be planned. However, when urgent the physician needs to do critical diagnostic evaluation, collect and send the samples for necessary diagnostic tests prior to any intervention. Once transfused, the accurate diagnosis of intrinsic red cell abnormalities may be greatly delayed.

Periodic review of etiology of severe anemia helps in planning and intensifying correcting programs. The present study is undertaken as evidence in India regarding severe anemia presenting to the hospital is inadequate in the recent past.

\section{Objective}

To identify the etiology of severe anemia $(\mathrm{Hb}<7 \mathrm{gm} / \mathrm{dL})$ in children, presenting to the tertiary care center.

\section{Subjects and Methods}

This is a retrospective record based study done at a tertiary care center. Institutional permissions were obtained for the study. All new severe anemia cases in the age group of 1 month to $18 \mathrm{yrs}$, which were admitted on Monday to the Department of Paediatrics at Niloufer Hospital from Jan 2017 to Dec 2017 were included. Previously worked up cases coming for transfusions and anemia due to bleeding were excluded. Anemia due to bleeding was excluded as the immediate cause of anemia is apparent and etiology require different workup. Details of history, physical examination and work-up were obtained for justification of diagnosis from case records, online reports, Complete blood picture registers, $\mathrm{Hb}$ electrophoresis register and bone marrow register. Comparative analysis of indices was not undertaken, as it has been a subject of debate, and the study's primary focus has been on etiology.

In microcytic anemia serum ferritin $(\mu \mathrm{g} / \mathrm{l})<12$ in $<5$ years of age, $<15$ in $\geqq 5$ years of age or transferrin saturation < $15 \%$ were used to diagnose IDA $[8,9]$. HbA2 value is $3.5-$ $8 \%$ in $\beta$-thalassemia trait (BTT). Patients with $\mathrm{HbA} 2 \geq 3.5 \%$ coincident with IDA considered as having IDA plus BTT. ${ }^{[10]}$ Where $\mathrm{Hb}$ electrophoresis and iron studies were unavailable in microcytic anemia, Mentzer index (MI) (mean corpuscular volume in $\mathrm{fl} / \mathrm{red}$ blood cell count in millions per cubic mm: <13 TT, >13 IDA) was used to describe probable etiology. Where mentzer index could not be used due to inadequate data, Shine and Lal $(\mathrm{S} \& \mathrm{~L})$ index $\left(\mathrm{MCV}^{2} \times \mathrm{MCH}\right.$ $\times 0.01$ : <1530 TT, >1530 IDA) was used. ${ }^{[1]}$

Patients suspected of megaloblastic anaemia on account of a raised mean corpuscular volume, were evaluated mostly by serum vitamin B12/folic acid assay, and in some by bone marrow examination. B12<221 pmol per litre was taken as deficiency. ${ }^{[12]}$ Folate deficiency was determined according to the testing lab reference $(<5.38 \mathrm{ng} / \mathrm{ml}) .{ }^{[13]}$ By using correlation of low MCV, high MCHC, and increased RDW when clinical features were present, diagnosis of HS was kept as no such patient in the study group underwent definitive evaluation. Malaria was diagnosed using parasite $\mathrm{V} \& \mathrm{~F}$ test when clinical features were present. Bone marrow examination was done wherever clinically indicated to diagnose marrow pathology.

Statistical analysis was done using SPSS software.

\section{Results}

Total number of patients included in the study is 112. Mean age was 3.94 yrs (+/_3.52) (Range: 1 month-13 years), median and mode were 3 years. 74 were male, 38 were female, and male to female ratio was 1.95:1(P-value $=0)$. Numbers of children according to age groups were: 1month1year-25 (22.3\%); 1-3yrs - 43 (38.4\%); 3-5yrs- 15 (13.4\%); 5-10yrs-20 (17.8\%) and >10 years $9(8 \%)$. Hb mean(+-SD) was $5.33 \mathrm{~g} / \mathrm{dL}(+/$ _1.34) Range1.8-7). Numbers of children according to confirmed or probable diagnosis are presented in [Table 1]. 


\begin{tabular}{|c|c|}
\hline Diagnosis & $\begin{array}{l}\text { Frequency } \\
(\%)\end{array}$ \\
\hline Confirmed IDA (BTT excluded by electrophoresis) MI>13 & $5(4.5)$ \\
\hline $\begin{array}{l}\text { Confirmed IDA (BTT excluded by electrophoresis), } \\
\text { MI }<13 / \text { S\&L Index }<1530 \text { ( } \alpha \text {-gene DNA analysis/BCB stain } \\
\text { not done } \\
\text { to exclude } \alpha \text {-Thalassemia trait) }\end{array}$ & $8(7.1)$ \\
\hline $\begin{array}{l}\text { Confirmed IDA (BTT excluded by electrophoresis) } \\
\text {-no indices-( } \alpha \text {-gene DNA analysis/BCB stain not done } \\
\text { to exclude } \alpha \text {-Thalassemia trait) }\end{array}$ & $1(0.9)$ \\
\hline Confirmed IDA (TT excluded by Mentzer index) & $5(4.5 \%)$ \\
\hline Confirmed IDA and BTT & $7(6.25 \%)$ \\
\hline Confirmed IDA and suspected TT(MI<13) & $7(6.25 \%)$ \\
\hline $\begin{array}{l}\text { Confirmed IDA with incomplete workup } \\
\text { (no indices-electrophoresis for exclusion of TT) }\end{array}$ & $6(5.35 \%)$ \\
\hline Suspected IDA (MI>13) (no iron studies/electrophoresis) & $12(10.7 \%)$ \\
\hline Suspected IDA (MI>13) (Hb electrophoresis-normal) & $6(5.35 \%)$ \\
\hline $\begin{array}{l}\begin{array}{l}\text { Folate deficiency (Coexistent with other disorders)(48 } \\
\text { tested) }\end{array} \\
\end{array}$ & $15(13.4 \%)$ \\
\hline B12 deficiency & $2(1.8 \%)$ \\
\hline BTT (IDA excluded) & $1(0.9 \%)$ \\
\hline BTT (IDA not excluded) & $5(4.5 \%)$ \\
\hline Suspected TT $(\mathrm{MI}<13)$ & $6(5.35 \%)$ \\
\hline Sickle cell disease/trait & 0 \\
\hline $\begin{array}{l}\text { Hereditary spherocytosis (HS) diagnosed by indices } \\
\text { and clinical features (Hb Electrophoresis normal in 3) }\end{array}$ & $8(7.1 \%)$ \\
\hline Marrow replacement by Acute leukemia & $7(6.25 \%)$ \\
\hline Aplastic anemia & $3(2.7 \%)$ \\
\hline Malaria & $3(2.7 \%)$ \\
\hline Antiretroviral therapy induced anemia & $1(0.9 \%)$ \\
\hline $\begin{array}{l}\text { Incompletely worked up (no indices, no further workup)/ } \\
\text { No Diagnosis }\end{array}$ & $19(17 \%)$ \\
\hline Total & 112 \\
\hline
\end{tabular}

\section{Discussion}

Anemia control should be an integral part of total health care and socioeconomic development of the developing countries. From the current statistics, still India is in need for more robust programs which address this problem. In this study, we investigated the etiology of severe anemia. The findings showed that male children are at double the risk of female children for having severe anemia. Most authors have shown that there is no difference in the prevalence of anemia or hemoglobin concentration in terms of sex. ${ }^{[14]}$ On the other hand, Torres et al. have demonstrated that the prevalence of anemia can vary between males and females; they have justified their findings by stating that "the higher prevalence of anemia among boys has to do with their higher growth rate; during the growth stage, their bodies demand a higher amount of iron, which cannot be supplied by the diet". ${ }^{14,15]} 60.7 \%$ of the children were 1 month to 3 years old. This is the age group, which is at high risk for severe anemia. Maternal iron deficiency will affect the breastfeeding infants. After the sixth month, iron stores are depleted and nutrition has a crucial role in the supply of this mineral to the infant. From the sixth to the twelfth month, iron requirements increase with body weight, as the infant's weight will have tripled by the end of the first year of life. Approximately $30 \%$ of the iron that is necessary for erythropoiesis should come from the food unlike $5 \%$ in adults who recycle iron. ${ }^{[14]} \mathrm{A}$ negative iron balance occurs if intake is inadequate. 39 (35\%) children had confirmed IDA, $18(16 \%)$ had suspected IDA, making a total of $57(51 \%)$ of severe anemia cases. The burden of preventable iron deficiency contributing to severe anemia cases is enormous, signifying the need for more effective programs to be implemented in India.

Folate deficiency (15 (13.4\% of total cases)) was observed in combination with IDA(10), suspected HS (3), and BTT (2) which can be prevented. $31 \%(15)$ of the cases tested for folate (48) had deficiency similar to a study. ${ }^{[16]}$ Even higher proportion of deficiency was seen in a study which showed folate deficiency in 263 of 416 children aged 12 - 59 months (63.2\%; 95\% CI: 58.5-67.7\%). ${ }^{[17]}$ This stresses the need for supplementation of folate to children with anemia irrespective of the cause. Though B12 deficiency is seen in $1.8 \%$ of the study population, much higher proportion of cobalamin deficiency ( $<150 \mathrm{pmol} / \mathrm{L})$ was detected in $36 \%$ of breastfed and $9 \%$ of nonbreastfed children in a study on children aged 6-30 months $(n=2482){ }^{[16]} 180$ of 469 children aged 12-59 months had B12 deficiency in another study $(38.4 \%$; $95 \%$ Confidence Interval (CI): 34.1$42.8 \%)^{[17]}$

Although nutritional anaemia and communicable diseases are major health priorities, thalassaemia and other haemoglobinopathies also pose a significant public health problem in India. In India, $\beta$-thalassaemia comprises about $80-90 \%$ of the total thalassaemias reported. ${ }^{[18]}$ The overall carrier rate for the whole of India is $3-4 \%$ for BT. Frequency for BTT is $1-17 \%$, with high frequencies of 5$17 \%$ in various groups. The overall prevalence of $\alpha$ thalassemia carriers (single $\alpha$ gene deletion) is around $13 \%$ but varies from $3 \%$ to $18 \%$ in the caste populations, however, it is very high in some tribal groups reaching over $90 \%$ in some groups. ${ }^{[19]}$ In the present study $13(11.6 \%)$ had confirmed BTT and 21 (18.75\%) had suspected TT. No case of thalassemia major was seen in the study. A major programme for education and creation of awareness is required throughout the country to prevent adverse forms of BT. This must target medical professionals, health care workers and the general public. There is a need for micromapping reaching out to the village level to get accurate figures on prevalence of thalassaemia. More centers for genetic counseling and prenatal diagnosis within reach to all couples must be established. ${ }^{[20]}$

The knowledge regarding HS, that it can be diagnosed by using indices, is not popular among practicing clinicians. Newly diagnosed patients with a family history of HS, typical clinical features (splenomegaly) and laboratory investigations (spherocytes, raised $\mathrm{MCHC}>/=36$, increase 
in reticulocytes, MCV $<80 \mathrm{fl}$, RDW $>15, \%$ hyperdense cells, \% Microcytes) do not require any additional tests. If the diagnosis is equivocal, e.g. where there are a few spherocytes on the film but no other laboratory, clinical or family evidence, a screening test with high predictive value for HS is helpful. The recommended screening tests are the cryohemolysis test and eosin-5-maleimide(EMA)binding. Confirmation of diagnosis may be necessary in selected cases if the screening tests produce an equivocal or borderline result. Gel electrophoresis analysis of erythrocyte membranes is the method of choice. ${ }^{[21-23]}$ Similar to our study, HS was the second most common cause of hemolytic anemia after thalassemias in an indian study. ${ }^{[24]}$

No case of sickle cell anemia presented with severe anemia in the study group, although in India the sickle cell gene has been reported in various studies as $73 \%$ in tribal people, $17 \%$ among scheduled castes, $9 \%$ among backward castes and $1 \%$ among developed castes. ${ }^{[25]}$ Malaria contributing to $2.7 \%$ of the cases in the study, continues to be a significant public health problem. Bone marrow disorders contributed to $9 \%$ of the cases in the study. Anemia in children receiving antiretroviral therapy (ART) should be monitored and intervened.

In developing countries of Africa malaria (95\%), IDA $(36.7 \%)$, and sickle cell anemia(31.7\%) were the predominant causes indicating significant regional differences in the etiology of severe anemia. ${ }^{[2,27]}$ China has lesser rates of anemia $(24.4 \%)$ compared to India. ${ }^{[28]}$ India has the highest IDA in comparison to rest of the world. Cereal dominant diet and low non-vegetarian food consumption in India are primarily responsible for the high magnitude of IDA contributing to severe anemia(51\% in the present study).

$26(23.2 \%)$ did not have hemogram indices, and of these cases $19(17 \%)$ did not undergo any further work up for etiology of anemia. Awareness of clinicians regarding usage of indices to suspect etiology is inadequate. Work up for anemia require investigations which may not be readily available in government sector, and may require expenditure by patient's family. Unaffordable patients may have to go without any diagnosis. This problem needs to be addressed by health administration of the country. Sampling and testing before transfusion is necessary for diagnosis, and requires commitment from health administration, and personnel to overcome this hurdle.

Though a number of nutrition based initiatives have been initiated in the country but to be effective and sustainable, these must be backed by firm political commitment and partnerships involving all relevant sectors including people and organisations. Efforts should be made by the concerned health departments and authorities to execute and supervise the functioning of the nutrition related schemes in an efficient way. A multi-intervention approach is needed encompassing adequate nutritional intake through dietary supplementation, food fortification and dietary modification, along with reduction of concurrent infection. There should be strengthening of Vitamin and Mineral Nutrition Information System (VMNIS) supported with firm political commitment. ${ }^{[29]}$

\section{Conclusion}

In conclusion IDA continues to be a common and important childhood health issue with its haematological and nonhaematological consequences. Studies have demonstrated that some of the changes occurring during period of brain growth $(<2$ years age) may be irreversible. Early recognition and diagnosis of IDA with appropriate interpretation of laboratory investigations is the key to the successful treatment of children with IDA. ID should be identified in patients with TT, and be treated promptly. Folate should be supplemented to all children with anemia irrespective of the cause. Paediatricians, administrators, and other health-care providers should thus work towards the prevention and elimination of IDA.Essential workup with proper interpretation of investigations for arriving at diagnosis prior to transfusing the child is obligatory.

\section{References}

1. National family health survey - 4 (2015-16). Ministry of Health and Family Welfare. Government of India. Available from: http://rchiips.org/NFHS/pdf/NFHS4/India.pdf Last accessed: 22/9/2018

2. The global prevalence of anaemia in 2011. Geneva: World Health Organization;2015.

3. Marisa Tucci, Jacques Lacroix, France Gauvin, Baruch Toledano, and Nancy Robitaille. Transfusion Medicine. In: Derek S. Wheeler, Hector R. Wong, eds. Pediatric Critical Care Medicine, Volume 3, 2nd Ed. London: Springer-Verlag; 2014

4. Chung-King Lin, Ling-Ping Chen, Hsiu-Lin Chang, Yung-Chuan Sung. Underestimation of the coexistence of iron deficiencies and thalassemia minors: a single institution experience in Taiwan. Kaohsiung Journal of Medical Sciences. 2014;30:409-414.

5. Tuphan Kanti Dolai, K. S. Nataraj, Nidhi Sinha, Sanjay Mishra, Maitreyee Bhattacharya. Malay Kumar Ghosh. Prevalance of Iron Deficiency in Thalassemia Minor: A Study from Tertiary Hospital. Indian J Hematol Blood Transfus. 2012 Jan-Mar;28(1):7-9

6. Madan N, Sikka M, Sharma S, Rusia U. Haematological parameters and $\mathrm{HbA} 2$ levels in beta-thalassaemia trait with coincident irondeficiency. Indian J Pathol Microbiol. 1998 Jul;41(3):309-13

7. Sarika Verma, Ruchika Gupta, Madhur Kudesia, Alka Mathur, Gopal Krishan, Sompal Singh. Coexisting Iron Deficiency Anemia and Beta Thalassemia Trait: Effect of Iron Therapy on Red Cell Parameters and Hemoglobin Subtypes. ISRN Hematology. Volume 2014, Article ID 293216, 5 pages http://dx.doi.org/10.1155/2014/293216

8. Serum ferritin concentrations for the assessment of iron status and iron deficiency in populations. Vitamin and Mineral Nutrition Information System. Geneva, World Health Organization, 2011. Available from: http://www.who.int/vmnis/indicators/serum_ferritin.pdf, Last accessed: 22/9/2018.

9. Elaine Chu Shan Chew, Joyce Ching Mei Lam. Diagnosis and management of iron deficiency anaemia in children - A clinical update. Proceedings of Singapore Healthcare. 2012; 21(4): 278-285.

10. Hannah Batterbee, Barbara De la Salle, Paul McTaggart, Caroline Doré, Barbara Wild, Keith Hyde. Evaluation of UK NEQAS (H) $\mathrm{Hb}$ A2 and related performance data. UK NEQAS (H) 2010. Available from: https://www.ukneqash.org/downloads/Hb\%20A2\%20Evaluation\%20Pro 


\section{Mendu d Srigade; Etialagy of Severe Anemia in Children}

ject_FINAL.pdf. Last accessed:22/9/2018.

11. Suad M. AlFadhli, Anwar M. Al-Awadhi, Doa'a AlKhaldi. Validity assessment of nine discriminant functions used for the differentiation between iron deficiency anemia and thalassemia minor. Journal of Tropical Pediatrics. 2007 Apr;Vol. 53(2): 93-97.

12. Ralph Green, Lindsay H. Allen, Anne-Lise Bjørke-Monsen, Alex Brito, Jean-Louis Guéant, Joshua W. Miller, et al. Vitamin B12 deficiency Nature Reviews Disease Primers volume3, Article number: 17040 (2017)

13. Erin McLean, Bruno de Benoist, and Lindsay H. Allen. Review of the magnitude of folate and vitamin B12 deficiencies worldwide. Food and Nutrition Bulletin. 2008; 29(2)(supplement).

14. Mônica M. Osório. Determinant factors of anemia in children. J Pediatr (Rio J). 2002;78 (4):269-78.

15. Torres MAA, Sato K, Queiroz SS. Anemia em crianças menores de dois anos atendidas nas unidades básicas de saúde no Estado de São Paulo, Brasil. Rev Saude Publica. 1994;28(1):290-4.

16. Taneja S, Bhandari N, Strand TA, Sommerfelt H, Refsum H, Ueland PM, et al. Cobalamin and folate status in infants and young children in a low-to-middle income community in India. Am J Clin Nutr. 2007 Nov;86(5):1302-9.

17. Umesh Kapil, G.S.Toteja, Ajeet Singh Bhadoria. Cobalamin and Folate Deficiencies among Children in the Age Group of 12-59 Months in India. Biomed J 2015;38:162-166

18. R.S.Balgir. The burden of haemoglobinopathies in India and the challenges ahead. Current science. 2000Dec; $79(11,10)$

19. Kanjaksha Ghosh, Roshan Colah, Mamta Manglani, Ved Prakash Choudhry, Ishwar Verma, Nishi Madan, et al. Guidelines for screening, diagnosis and management of Hemoglobinopathies. Indian J Hum Genet. 2014 Apr-Jun;20(2):101-119.

20. Management of haemoglobin disorders. Report of a joint WHO-TIF meeting; 2007 Nov 16-18; Nicosia, Cyprus. World Health Organization; 2008
21. Bolton-Maggs P.H., Stevens R.F., Dodd N.J., Lamont G., Tittensor P., King M.J.. Guidelines for the diagnosis and management of hereditary Spherocytosis. British Journal of Haematology. 2004;126:455-474

22. Bolton-Maggs PH, Langer JC, Iolascon A, Tittensor P, King MJ. Guidelines for the diagnosis and management of hereditary spherocytosis_-2011 update. Br J Haematol 12;156(1):37-49.

23. A Barbullushi, P Daja, D Bali, N Maliqari, A Godo. Hereditary spherocytosis and red cell indices mchc, mcv, rdw. Arch Dis Child 2014;99(Suppl 2):A143

24. Chaitra Venkataswamy, AM Shanthala Devi. Clinico-Haematological Profile of Hereditary Haemolytic Anaemias in a Tertiary Health Care Hospital in South India. Journal of Clinical and Diagnostic Research. 2017 Jun;11(6): EC17-EC21

25. Kaur M, Dangi CBS, Singh M, Singh H, Kapoor H. Burden of sickle cell disease among tribes of India : A burning problem. Int Res J Pharm App Sci 2013; 3(1) : 60-80.

26. Tinuade Ogunlesi, Bolanle Fetuga, Michael Olowonyo,Adesola Adekoya, Oluseyi Adetola, Adebimpe Ajetunmobi. Severe childhood anaemia and blood transfusion in a nigerian secondary level facility. Journal of Tropical Pediatrics, 2016, 62, 107-115.

27. Kwadwo A. Koram, Seth Owusu-Agyei, Greg Utz, Fred N. Binka, J. Kevin Baird, Stephen L. Hoffman, et al. Severe anemia in young children after high and low malaria transmission seasons in the kassenanankana district of northern Ghana. Am. J. Trop. Med. Hyg., 62(6), 2000, pp. 670-674.

28. Qian-Qian Xin, Bo-Wen Chen, De-Lu Yin, Feng Xiao, Rui-Li Li, Tao Yin, et al. Prevalence of anemia and its risk factors among children under 36 months old in China. Journal of Tropical Pediatrics, 2017, 63, $36-42$.

29. Ravi Prakash Upadhyay, Palanivel C and Vaman Kulkarni. Unrelenting burden of anaemia in India: Highlighting possible prevention strategies. International Journal of Medicine and Public Health. 2012 Oct-Dec;2(4).

Copyright: (c) the author(s), publisher. Asian Journal of Clinical Pediatrics and Neonatology is an Official Publication of "Society for Health Care \& Research Development". It is an open-access article distributed under the terms of the Creative Commons Attribution NonCommercial License, which permits unrestricted non-commercial use, distribution, and reproduction in any medium, provided the original work is properly cited.

How to cite this article: Mendu SB, Srigade V. Etiology of Severe Anemia in Children at a Tertiary Care Hospital. Asian J. Clin. Pediatr. Neonatol.2018;6(2):7-11.

DOI: dx.doi.org/10.21276/ajcpn.2018.6.2.3

Source of Support: Nil, Conflict of Interest: None declared. 